\title{
Use of Energy Storage for Levelling Wind Generation - a Parametric Approach Concerning the Capacity of the Storage
}

\author{
Bálint Hartmann ${ }^{1}$ and András Dán, Dr. ${ }^{2}$ \\ ${ }^{1}$ Department of Electric Power Engineering \\ Budapest University of Technology and Economics \\ 1111, Egry J. u. 18., Budapest (Hungary) \\ E-mail: hartmann.balint@vet.bme.hu \\ ${ }^{2}$ Department of Electric Power Engineering \\ Budapest University of Technology and Economics \\ 1111, Egry J. u. 18., Budapest (Hungary) \\ Phone: +36 1463 3019, E-mail: dan.andras@vet.bme.hu
}

\begin{abstract}
Present paper examines the connection of wind generation and energy storage. Since 2007, all generator unit in Hungary has to present a schedule on its forecasted production in 15-minutes detail. If the production exceeds certain area (currently $\pm 50 \%$ ) of the schedule, a penalty-tariff is to be paid for the ISO. The forecasting methods available of present sometimes not precise enough, thus to avoid this penalty-tariff, use of energy storage may be a possible solution. A computer simulation tool was prepared formerly to calculate the difference in production and schedule, the income, and penaltytariffs. Results have shown that optimal size of storage capacity mainly depends on the power of the generator and the penalty tariffs. It has also been investigated what prices the system operator can enforce to encourage producers to use a storage unit.

Another aim of the paper is to investigate whether certain sitespecific wind parameters can correlate with the size of the needed storage. The goal is to find cornerstones for sizing for different storage methods.
\end{abstract}

\section{Key words}

Distributed generation, energy storage, market regulation, wind energy

\section{Introduction}

The role and support of renewable energy sources have increased rapidly over the last years because of raising energy demand, energy dependency, increasing and variable energy prices and concern about climate change. In 2008 in the European Union 8.484 MW wind power capacity was installed, which was $36 \%$ of the total new electricity generating capacity, a greater annual capacity than in any other electricity generating technology. [1] At the end of 2008 the cumulative wind power capacity raised to $65 \mathrm{GW}$ in the EU-27 (8\% of the total capacity of EU), but because of the low capacity factors of wind power plants it only produced $4.2 \%$ of electricity demand. [2] Amongst applications using renewable energy sources it has one of the smallest environmental impacts, which is not only favourable for the environment, but also helps with authorization procedures. Its payback is guaranteed by supporting schemes in most EU Member States. The EU is still the strongest market for wind energy development, though in 2007 the majority $(\sim 57 \%)$ of new installed wind capacity was outside Europe for the first time. At the end of 2008 the global cumulative capacity was $120.798 \mathrm{GW}$.

\section{Storage Tasks}

Present paper focuses on three different storage methods, with three different operation goals. As it will conclude, these tasks sometimes require significantly different sizes concerning the power and/or energy rating of the storage. It also must be pointed out, that there are several technologies available on the market, some of them suiting our goals well, while others not. The late developments are also able to decouple the power and energy rating of the storage as well (e.g. concerning flow batteries, energy depends on the amount of electrolyte, while power is determined by the cell stack). The technology will however be only taken into account in connection with the first storage task, when price is also in focus.

\section{A. Regulating to follow schedule}

Short-term forecasting (for the upcoming 48-72 hours) is needed for power system management, for scheduling optimization of conventional plants, and it is also needed for a more efficient energy market. In Hungary, from 2007, all energy producers - including renewables - were obliged to present schedules for their production. These must include the real power every 15 minutes. The schedule has to be presented for the following month; otherwise a penalty of $26.11 \mathrm{EUR} / \mathrm{MWh}(7 \mathrm{Ft} / \mathrm{kWh})$ has 
to be paid. The penalty is $18.65 \mathrm{EUR} / \mathrm{MWh}(5 \mathrm{Ft} / \mathrm{kWh})$ if a schedule was presented, but generation level exceeds the $\pm 50 \%$ value compared to the schedule. In 2008, possibility of day-ahead rescheduling was introduced, and the deadline was set to 11. a.m. the previous day. [3] To avoid - at least part of - the penalty-tariff, there are two widely used solutions. The first is to increase the accuracy of prediction. This can be reached through the use of better Numerical Weather Prediction (NWP) models, use of more weather forecasts or use of longer forecast horizon. Another way is to use some kind of energy storage, trying to level the output of the turbine, before it is injected into the grid.

In this case, the task of the storage is to try to balance the real power in every 15 minutes, which can be charge or discharge. The goal is to find out, how much a storage my cost, to become a cost-effective solution on longer range (10-20 years).

\section{B. Regulating to follow constant output}

In some cases, no meteorological data is available to prepare a weather forecast, and a production schedule. It also happens that these kinds of data are available, but lack accuracy, so use of them is not reasonable. In this case, a possible opportunity is to keep the power inside a pre-set and constant range, for example in the $\pm 10 \%$ range of the average power.

If we set this value to $\pm 50 \%$, we are able to compare this storage method with the previous one - in this case, the average power would be given as a constant schedule value.

\section{Regulating to minimal supported power}

Another possible choice for the producer is to choose to support at least a specified amount of power at a specified confidence level. This may be a good solution for wind turbines with high variation of wind power, and long period with no production at all. However, this storage task requires significantly higher energy rating then the previous ones.

\section{Computer Simulations}

To process wind data a computer simulation tool has been prepared previously which uses Matlab as base software. The former version was capable of calculating the difference in production and schedule, the income and the penalty-tariff. The current version is a slightly modified one, to better suit other storage methods than following schedule. It has to be emphasized, that the main goal of the simulation tool is not finding the best storage methods, but to represent a simple but real way of operation. There are many variable parameters included in the script though, they are both technological (round cycle efficiency, level of allowed deep discharge) and financial (feed-in tariffs), as described in detail in [5].

The measurement data for current investigation has been received from Imre Szilágyi, Operations \& Maintenance Director of the Hungarian MOVHR-1 wind farm, and Antal Balogh, Technical Director. The wind farm consists of 12 Gamesa G90 units, with a total power of $24 \mathrm{MW}$. The measurement data consists of an 8 month period in 2008, between February and September. The operators receive two different weather forecasts. One of them is presented by the Hungarian Meteorological Service (HMS) while the other is received from a Spanish private company, Meteológica. According to $\mathrm{Mr}$. Balogh, they use these as a basis for their own schedule. Since this wind farm is among the few ones, that buys weather forecast data, they have proven to be a good choice for such simulations.

\section{Results}

\section{A. Regulating to follow schedule}

This simulation is the only one in present paper, that deals with the financial side of the investment of a storage device. The energy that is produces by the wind farm is bought by the system operator on pre-set prices. This feed-in price in 2010 is $119.77 \mathrm{EUR} / \mathrm{MWh}$ (32.1 Ft/kWh), 107.16 EUR/MWh (28.72 Ft/kWh) and 43.73 EUR/MWh (11.72 Ft/kWh) in the peak, off-peak and night off-peak periods respectively. The penaltytariff is the same value for years, as mentioned above.

We approximate, that the feed-in price is constant all the time, and use a value of 106,3 EUR/MWh which was calculated proportionately. For storage, technological data and costs of a VRB flow battery was used, based on [6]. The cycle efficiency was set to $70 \%$, while costs of the unit are the following: $500 \$ / \mathrm{kW}$ for the cell stack, $150 \$ / \mathrm{kWh}$ for the electrolytes, and fixed and variable O\&M costs of $2 \$ / \mathrm{kW} /$ year and $0.029 \$ / \mathrm{kWh} /$ year respectively. Calculations were made for a 20 year period. As Fig 1. shows, using a storage unit would not be cost-effective even in the long run. The main reasons of this are the low penalty-tariffs, and the loose regulations, that require power to be inside the $\pm 50 \%$ range of the schedule.

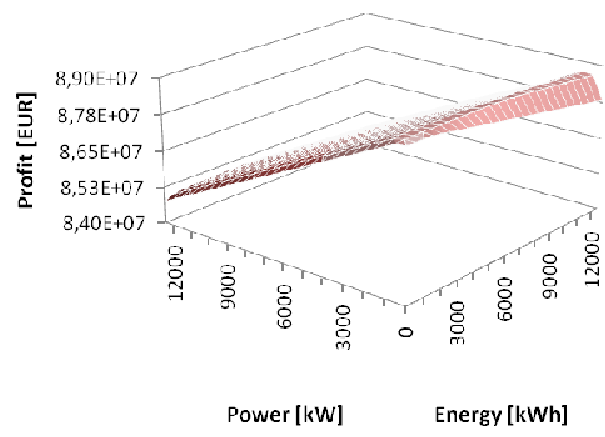

Fig 1. Profit of 20 years, penalty-tariff 18.65 EUR/MWh

To make storage a cost-effective alternative, the regulator would have to modify the tariff system, for example to raise the penalty-tariff. With this move, the best choice would be to use a $2000 \mathrm{~kW} / 12000 \mathrm{kWh}$ storage, as it is indicated by Fig 2 . as well. 


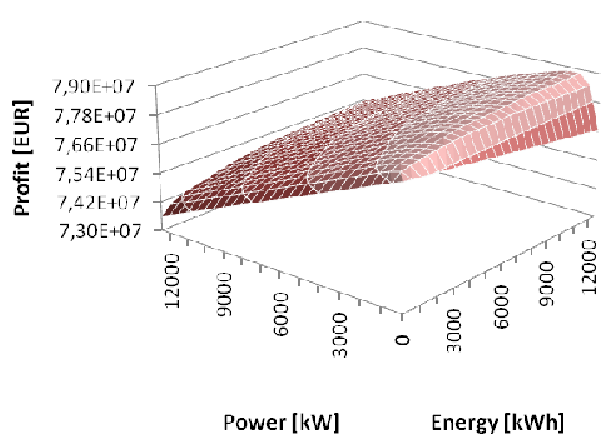

Fig 2. Profit of 20 years, penalty-tariff 37.3 EUR/MWh

By using this kind of storage method, and building a $2000 \mathrm{~kW} / 12000 \mathrm{kWh}$ unit, we are able to avoid penaltytariffs during $35.79 \%$ of the time.

\section{B. Regulating to follow constant output}

If our aim is to keep the produced energy within certain limits as much of time as we can, the result will highly depend on the statistical behaviour of the wind at the site that is under investigation. At the MOVHR-1 wind farm, the average power is $4970 \mathrm{~kW}$, which is only around $20 \%$ of the nominal power. The highest production during the period under investigation was $21480 \mathrm{~kW}$, so the wind farm is almost never able to reach maximal output.

In the first scenario, the target output power is the $\pm 10 \%$ range of the average power, namely $4473-5467 \mathrm{~kW}$. Without any kind of storage, the generation of the wind farm is between these two limits $4.78 \%$ of all time. By using storage of certain size, this value can be increased. Fig 3. shows the result of this calculation, with both power and energy treated as a variable. Cycle efficiency of the storage is set to $100 \%$.

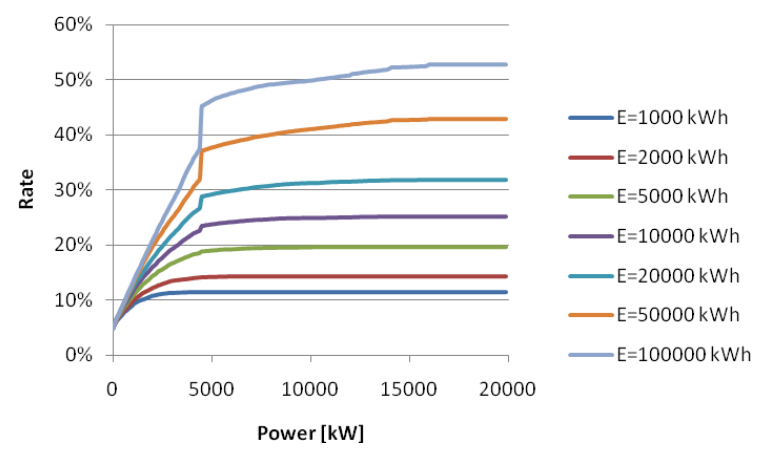

Fig 3. Effect of power on efficiency of storage

As the Fig shows, at lower energy levels power is not really a limiting factor, the graphs saturate at around $3500-4000 \mathrm{~kW}$. As we increase energy rating, and reach virtually infinite capacity, a step can be observed in the graphs. This occurs between 4400 and $4500 \mathrm{~kW}$. The reason behind this is quite clear: at high percent of the time, level of production is around zero. If we would like to produce at least $90 \%$ of the average power we need $4473 \mathrm{~kW}$ power, and sufficient energy. If we possess both of them, very high level of the output can be between the pre-set limits. Of course, when dealing with a real storage device, the round cycle efficiency will never be as good as $100 \%$. As we decrease the variable of efficiency in the simulation, while keeping the energy rating at a constant level, the graphs will show a shrinking tendency, as it can be seen on Fig 4. as well.

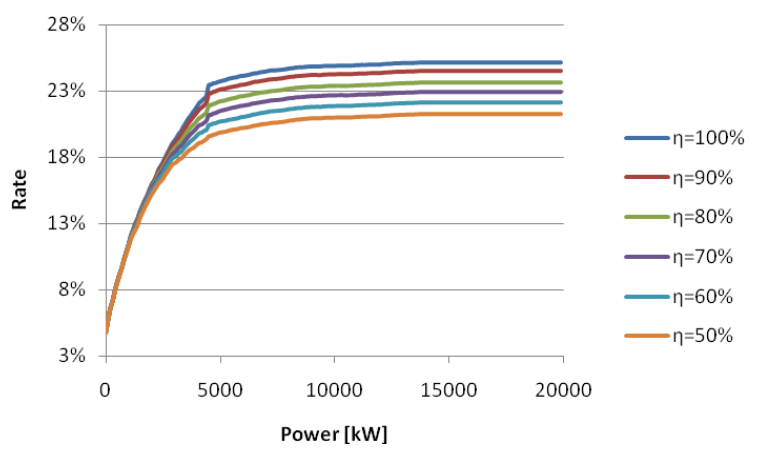

Fig 4. Effect of cycle efficiency, $E=10000 \mathrm{kWh}$

It may be also observed, that at such energy rating, the cycle efficiency does not have a significant effect, for example the difference between $\eta=100 \%$ and $\eta=70 \%$ (let's say, VRB flow battery) is around $2 \%$ at the highest power ratings. If we perform the simulations for other power limits, like $\pm 20 \%, \pm 30 \%$ and so on, results will follow the same logic. Another examination was carried out by modifying the time function of the power produced by the turbine. For example, when virtually switching the first and the second part of the month (so the first 15 days will end the month and the last 15 days will start it), the result of the simulation will be exactly the same graph, the significant step will be again between 4400 and $4500 \mathrm{~kW}$, and so on. The experiences are the same, when splitting the time function of the power into arbitrary segments, and organizing them randomly. So it can be stated, that power rating of the necessary storage unit depends mainly on the target value of the desired output power.

The question of the energy rating is much more complicated. If we set power of the storage as a fixed value during the simulation, and use energy of the storage as an increasing variable, the rate of the time, when the output power is between the desired limits, will increase monotonously, until it reaches $100 \%$. Of course this will only occur at irrationally high capacity, as it can be introduces through a simple example. Let's take, that the storage is fully charged, when the wind stops blowing, and the production of our wind farm suddenly reaches zero. If we want to supply the average power (4970 kW) every hour without the wind blowing will use up $4970 \mathrm{kWh}$ energy from our storage. During the period of the data collection, there were several occasions, when the weather was dead calm for more hours, or even a day. If we have to supply from the storage for 24 hours, we need almost $120000 \mathrm{kWh}$ energy to fulfil the requirements. Fig 5. indicates this tendency. 


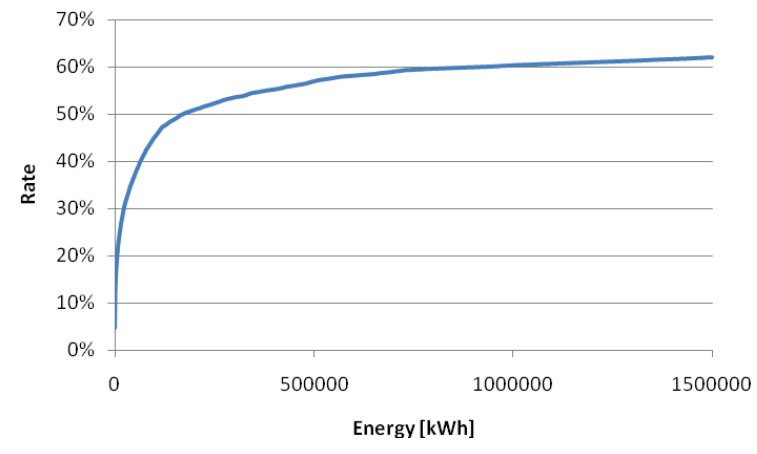

Fig 5. Effect of energy, $\mathrm{P}=4500 \mathrm{~kW}$

Since the graph is monotonous and shows no sign of steps, we have to investigate other parameters as well to determine the best suiting energy ratings. One useful parameter is the length of each period, when the power of the turbine is outside the targeted range, and thus use of the storage is needed. The longer these periods are, the more likely to be that higher amount of energy is needed to keep the output power within range (likely, because it will also be affected by the regulating power). In case of the original measurement data, the average length of the periods is 197 minutes when turbine power surpluses the needs, and 332 minutes when turbine power is insufficient. It is reasonable, that the shorter these periods are, the more time the output power will be in the desired range.

This can be observed by modifying the time function of power, so as regulation periods become shorter. A simple way was mentioned three paragraphs earlier. An examination was done, by splitting the time function into random number of segments, and organizing them randomly. Power and energy rating was treated as a fixed variable, and the output was again the rate of time, the output power stays in the desired range. As it can be seen on Fig 6., the graphs look very similar, the only significant difference is caused by the different energy rating. The graphs are not monotonous though, at low period lengths, the rates start to decrease. This is caused by the method of splitting of the time function. When the average length of regulation periods is around 2-3, the time function is almost completely randomized data point by data point, which is of course not what like under real circumstances.

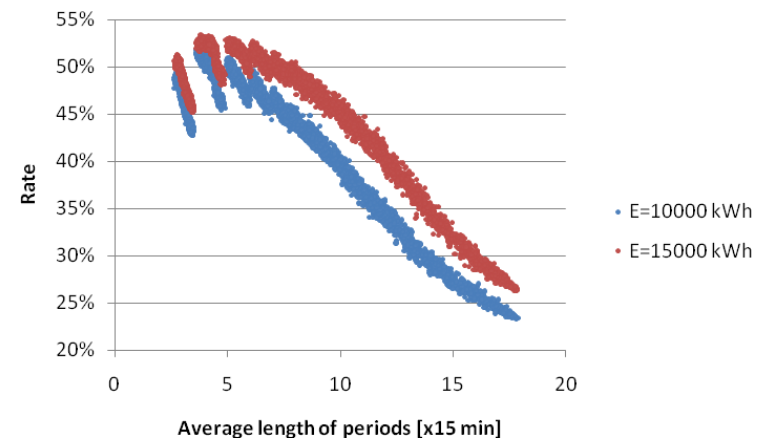

Fig 6. Correlation between the regulation period and the rate of time, $\mathrm{P}=4500 \mathrm{~kW}$
Based on these results we can conclude, that if we know statistical data of wind speed, like the average generated power, the average length of the regulation periods, target range of the output power, and the desirable rate of time for the regulation, we can give a good approximation of the energy rating of the storage.

Another interesting question is to compare this storage method with the previous one. It was stated above, that by regulating to follow the (varying) schedule, we were able to avoid penalty-tariffs during $35.79 \%$ of the time. If we present the average power of the site as (a constant) schedule, and use the same size of storage $(2000 \mathrm{~kW} / 12000 \mathrm{kWh})$, we are able to reach $36.07 \%$, so the two methods result almost the same, regarding technical parameters.

\section{Regulating to minimal supported power}

Since one of the main drawbacks of wind power utilization is their high weather dependence, it looks reasonable to bring some confidence into the field. For example, if the main problem of the system operator is insufficient generation capacity, it may ask some of the producers, to guarantee certain amount of power, certain part of the time (e.g. $50 \%$ of the nominal power is required to be available $95 \%$ of the year). Because many wind farm sites (especially in Hungary) lack high wind speeds, a possible use of energy storage for them is to become part of this guaranteed capacity. The two main questions arise in connection of the amount of guaranteed power and the confidence of the availability. The first one affects mainly the power rating of the storage, while the second one correlates more with the energy rating. For example, if our target is to support $90 \%$ of our average power (which is $4970 \mathrm{~kW}$ ), building a storage with rated power around $4473 \mathrm{~kW}$ will prove to be sufficient in most of the time, even in periods, when there is no power generation by the wind turbine. For present paper, we have chosen parameters so as to highlight a possible use of small size storages as well. Fig 7. shows the needed power and energy rating is we guarantee to support 10,20 or $30 \%$ of our average power with $75 \%$ confidence level.

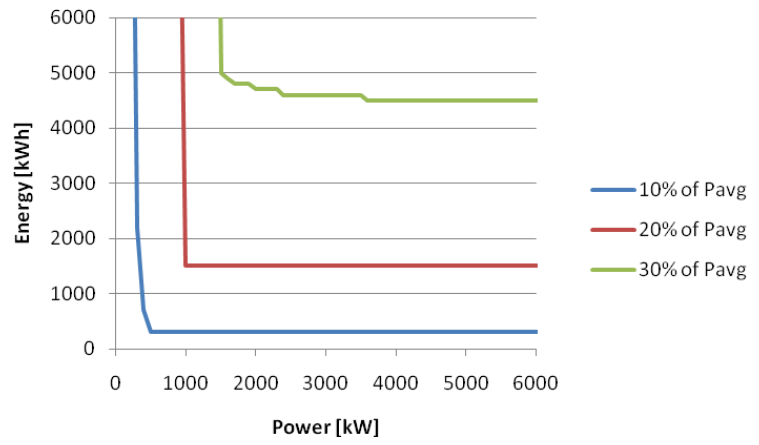

Fig 7. Regulating to minimal supported power, $75 \%$ confidence

As it can be seen, even a quite small storage unit may prove sufficient to ensure, that there is always some power injected into the grid. 


\section{Conclusion}

Present paper deals with both technical and financial issues of energy storage. It has been concluded, that mainly due to the regulations that are becoming less strict year by year, it is not a cost effective solution in Hungary to build a storage, that aims to decrease the difference between scheduled and produced wind power.

The two other storage methods are using fixed target ranges for output power. Is has been investigated, what effects do power and energy ratings individually have on the efficiency of the storage process. The results have shown, that in such cases, power rating of the storage unit may be treated independently from energy rating, and may be determined only by using statistical data, and no time function.

Future work will include investigation of the correlation between the length of the average regulation period and the rate of time, the storage operates in the desired range.

\section{References}

[1] EWEA (European Wind Energy Association), Wind Energy Statistics 2008, [Online].

Available: http://www.ewea.org/fileadmin/ewea do cuments/documents/publications/factsheets/EWEA _FS_Statistics.pdf
[2] GWEC (Global Wind Energy Council), Global Wind Energy Outlook, [Online].

Available: http://www.gwec.net/fileadmin/documen ts/Publications/GWEO_2008_final.pdf

[3] Hungarian Electricity Act 2007, Government Regulation Nr. 273/200; 389/2007; 109/2007

[4] B. Hartmann, Zs. Csetvei, "Support Policies Regarding Wind Generation, and Use of Storage Technologies from the Viewpoint of the TSO", presented at the $9^{\text {th }}$ International Conference on Heat Engines and Environmental Protection, Balatonfüred, Hungary, 2009

[5] B. Hartmann, Zs. Csetvei, A. Dán, Dr. "The Scheduling Methods of Wind Generator Production, and Use of Storage Technologies to Avoid Penalty Tariffs", presented at the $2^{\text {nd }}$ International Youth Conference on Energetics, Budapest, Hungary, 2009

[6] Handbook of Energy Storage for Transmission or Distribution Applications, EPRI, Palo Alto, CA., 2002 [Online]

\section{Acknowledgement}

The authors wish to thank for the financial support provided for this research project by the Foundation for the Education of Energy Engineers. 